\title{
Water-soluble poly(3-hydroxyalkanoate) sulfonate: versatile biomaterials used as coatings for highly porous nano-MOF
}

\author{
Jain Caroline 1, 2, Li Xue ${ }^{3}$, Houel Renault Ludivine 4, Modjinou Tina ${ }^{1}$, Simon Colin Christelle ${ }^{2}$, \\ Gref Ruxandra ${ }^{3}$, Renard Estelle ${ }^{1}$, Langlois Valérie ${ }^{1, ~ *}$
}

\begin{abstract}
1 Institut de Chimie et des Matériaux Paris-Est, UPEC-CNRS, 2 rue Henry Dunant, 94320 Thiais, France

2 Ifremer, UMR 6197, Laboratoire de Microbiologie des Environnements Extrêmes (LM2E), Technopôle

Pointe du Diable, 29280 Plouzané, France

3 Institut des Sciences Moléculaires d'Orsay, UMR 8214, CNRS-UPS, Rue André Rivière, 91405 Orsay, France

${ }^{4}$ Centre Laser de I'Université Paris-Sud (CLUPS/LUMAT), CNRS-UPS-IOGS, Université Paris-Saclay, 91405 Orsay, France
\end{abstract}

* Corresponding author : Valérie Langlois, email address : langlois@icmpe.cnrs.fr

\begin{abstract}
:
Water soluble poly(3-hydroxyalkanoate) containing ionic groups was designed by two successive photoactivated thiol-ene reactions. Sodium-3-mercapto-1-ethanesulfonate (SO3-) and poly(ethylene glycol) methyl ether thiol (PEG) were grafted onto poly(3-hydroxyoctanoate-co-3-hydroxyundecenoate) $\mathrm{PHO}(67) \mathrm{U}(33)$ to both introduce ionic groups and hydrophilic moieties. The grafted copolymers PHO(67)SO3-(20)PEG(13) were then used as biocompatible coatings of nano-Metal Organic Frameworks surface. Scanning Electron Microscopy and Scanning Transmission Electron Microscopy coupled with Energy Dispersive X-ray characterizations have clearly demonstrated the presence of the copolymer on the MOF surface. These coated nano-MOF are stable in aqueous and physiological fluids. Cell proliferation and cytotoxicity tests performed on murine macrophages J774.A1 revealed no cytotoxic side effect. Thus, biocompatibility and stability of these novel hybrid porous MOF structures encourage their use in the development of effective therapeutic nanoparticles.
\end{abstract}

Keywords : Polyhydroxyalkanoates, PHOU, thiol-ene photoactivated, PEG, MOF, nanoparticles 


\section{INTRODUCTION}

Poly(3-hydroxyalkanoates) (PHAs) are biodegradable polymers synthesized by many organisms, especially prokaryotes. There are over 150 types of these polyesters, accumulated as carbon and energy storage material in a wide variety of bacteria. PHA granules are produced when microorganisms are cultivated in the presence of both carbon source excess and nitrogenous nutrient deficiency. ${ }^{1-2}$ According to the length of side chains, different types of PHAs can be classified as either a short chain length, scl-PHAs, a medium chain length, mclPHAs and lcl-PHA, long chain length. Physical properties are related to the length of these side chain; thus, scl-PHAs are semi-crystalline, rigid and brittle whereas mcl-PHAs are soft and elastomeric.

Over the last three decades, biomaterials based on PHAs have been developed for medical or pharmaceutical applications ${ }^{3-12}$ such as tissue engineering, implants or drug delivery carriers due to their proven biodegradability, biocompatibility and lack of toxicity. In order to enlarge the potential in biomedical applications, many chemical modifications have been developed. Among them, the combination of the properties of hydrophobic PHA and hydrophilic PEG was used to prepare amphiphilic PHAs. The excellent water-solubility and biocompatibility of PEG, encouraging the use of this polymer in biomedical applications. ${ }^{13-15}$ Moreover PEG having molar mass in the range of 2,000-5,000 g/mole confers a long blood-circulation ability by reducing both nanoparticles accumulation in liver and spleen, and mononuclear phagocyte system uptake (stealth behaviour), ${ }^{16}$ in order to avoid in vivo nanoparticles rapid elimination. Micro- and nanoparticles based on amphiphilic PHA-block-PEG copolymer have been extensively studied as drug delivery system. ${ }^{17-28}$ PEGylation of PHAs can be performed by chemical modifications or by bioprocessing in vivo, bioPEGylation. Regarding the chemical way, block copolymers were synthesized by direct transesterification or by using telechelic oligomers based on PHAs. A series of amphiphilic diblock and graft PEG-PHA copolymers were recently prepared through a click chemistry approach. ${ }^{21-22}$ Another way to improve hydrophilicity or water-solubility of organic compound is to introduce ionic groups as carboxylic groups, ${ }^{29}$ ammonium groups, ${ }^{30} \mathrm{~N}$-acetyl-L-lysine ${ }^{31}$ and sulfonate functions. ${ }^{32}$ The sulfonate anionic sites are known to display biological interactions and they can interact with proteins. ${ }^{33}$ A series of PHAs sulfonate have been prepared using the highly versatile approach as photoactivated thiol-ene or thiol-yne reactions. These new amphiphilic scl-PHAs oligomers were able to self-assemble in aqueous solution whereas the sulfonate derivatives of mcl-PHAs are totally soluble in water if the content of sulfonate groups is superior to $25 \%$ whatever the molar mass of the PHAs. ${ }^{32}$ In this context, we used here the large versatility of the thiol-ene 
reaction to introduce both sulfonate groups and PEG grafts. It has already been demonstrated that the PHAs having unsaturated groups in the side chains are very useful to introduce reactive groups by using thiol-ene reactions. Poly(3-hydroxyoctanoate-co-3-hydroxyundecenoate) $\mathrm{PHO}_{(67)} \mathrm{U}_{(33)}$ is a functionalized mcl-PHA bearing molar ratio $33 \%$ of terminal alkene units on its side chains. First, thiol containing sulfonate groups were reacted with unsaturated PHAs. In a second step, the PEG grafting was achieved via a similar thiol-ene addition, which has proven to be an effective reaction to chemical modify the unsaturated PHAs. ${ }^{22,31,34}$

The objective here was to propose a versatile biodegradable and biocompatible polymeric coating for highly porous nanosized metal organic frameworks (nanoMOFs). NanoMOFs, formed by strong coordination between metal ions and organic ligands, recently emerged in the world of therapeutic nanovectors. ${ }^{35-39}$ In particular, iron trimesate nanoMOFs MIL-100(Fe) (MIL stands for Material from Institut Lavoisier) have large surface areas allowing to load a large variety of drugs able to penetrate within the porous MOF structures. ${ }^{40-41}$ These porous solids are built up from $\mathrm{Fe}(\mathrm{III})$ octahedra trimers and trimesate linkers (1,3,5-benzene tricarboxylate) that self-assemble to build a porous architecture delimiting large (29 $\AA)$ and small (24 $\AA$ ) mesoporous cages. The two types of cages are accessible for drug adsorption inside the 3D-porosity through pentagonal $(5.6 \AA)$ and hexagonal windows $(8.6 \AA)$. Due to the presence of $\mathrm{Fe}$ and free water molecules in their structure, they acted as efficient $\mathrm{T}_{2}$-weighted contrast agents for Magnetic Resonance Imaging (MRI) of interest for theranostics. ${ }^{42}$ The lack of toxicity of MIL-100(Fe) nanoMOFs has been established in vivo after repetitive administrations. ${ }^{43-45}$ These materials offer a particular hydrophilic/hydrophobic microenvironment inside their open porosity, allowing the incorporation of a large variety of either water-soluble or hydrophobic active molecules, by simple one-step impregnation, generally without organic solvent. ${ }^{41-42}$

For last five years, there has been an intensive research in coating nanoMOFs in order to prevent premature drug release, improve colloidal stability, and control the in vivo fate. For instance, oligomers or polysaccharides (cyclodextrin, heparin, hyaluronic acid or chitosan), 43,44,46-49 dioleyl-phosphocholine lipid ${ }^{50}$ or polycaprolacton ${ }^{51}$ were used. Of main interest, PEG grafting onto MOF nanoparticles surface was also performed to generate stealth material against immune system. ${ }^{43,52-54}$ We here developed a new hybrid system, composed of nanoporous MIL-100(Fe) nanoMOF coated by a water-soluble PEGylated PHA containing sulfonate groups that should be able to strongly interact with nanoMOF. Thus, all or part of PHOU lateral unsaturations were first functionalized with $\mathrm{SO}_{3}{ }^{-}$and $\mathrm{PEG}$ groups, in order to improve watersolubility and achieve efficient PEG grafting as well as metal interactions between 
functionalized PHA and MOF. Then, MOF-PHA hybrid nanoparticles were synthesized by a rapid one-step non-covalent method or impregnation, and their structure was investigated by complementary physicochemical methods. More particularly, for the first time, scanning transmission electron microscopy (SEM-STEM) using energy dispersive X-ray (EDX) spectroscopy was used to unravel the structure of the coated nanoMOFs and enable gaining information on the coating location. Cell proliferation and cytotoxicity tests were carried out on murine J774.A1 macrophages to evaluate MOF-PHA hybrid porous nanoparticles toxicity.

\section{MATERIALS AND METHODS}

\subsection{Materials}

Dimethyl sulfoxide (DMSO), methanol (MeOH) and tetrahydrofurane (THF) were obtained from VWR International. 2,2-dimethoxy-2-phenylacetophenone (DMPA), sodium-3-mercapto1-ethanesulfonate $\left(\mathrm{SO}_{3}{ }^{-}\right)$, poly(ethylene glycol) methyl ether thiol (PEG, molar mass: 2,000 g.mol ${ }^{-1}$ ) were purchased from Sigma Aldrich. Dialysis membranes (MWCO 1 and 6-8 KDa) were procured from Spectrumlabs. Poly(3-hydroxyoctanoate-co-3-hydroxyundecenoate) $\mathrm{PHO}_{(67)} \mathrm{U}_{(33)}$ was provided from HES-SO Valais-Wallis, Switzerland.

\subsection{Synthesis of $\mathrm{PHO}_{(67)} \mathrm{U}_{(13)} \mathrm{SO}_{3_{(20)}^{-}}$}

$100 \mathrm{mg}$ of $\mathrm{PHO}_{(67)} \mathrm{U}_{(33)}\left(\mathrm{Mn}=40,000 \mathrm{~g} / \mathrm{mol}, 2.13 \times 10^{-4} \mathrm{~mol} \mathrm{C}=\mathrm{C}\right)$ and $0.2 \mathrm{eq}$ of photoinitiator DMPA $/ \mathrm{C}=\mathrm{C}$ were dissolved in $6 \mathrm{~mL}$ of THF (Solution 1). On the other hand, 1.2 eq of $\mathrm{SO}_{3}{ }^{-}$ $/ \mathrm{C}=\mathrm{C}$ were solubilized in $6 \mathrm{~mL}$ of $\mathrm{MeOH}$ then adding $3 \mathrm{~mL}$ of THF drop by drop (Solution 2). Solution 2 was mixed with the first and the resulting mixture was irradiated during $10 \mathrm{~min}$ at room temperature by Lightning cure LC8 (L8251, Hamamatsu) equipped with a mercury-xenon lamp $\left(180 \mathrm{~mW} . \mathrm{cm}^{-2}\right)$ coupled with a flexible light guide whose end was placed $11 \mathrm{~cm}$ from the sample. At last, $30 \mathrm{~mL}$ of DMSO were added to the resultant solution before purification by dialysis (MWCO 1,000 Da) against $2 \mathrm{~L}$ of water for 2 days with 4 water changes per day, followed by freeze-drying (yield 86\%).

\subsection{Synthesis of $\mathrm{PHO}_{(67)} \mathrm{U}_{(7)} \mathrm{SO}_{3_{(20)}^{-}} \mathrm{PEG}_{(6)}$ and $\mathrm{PHO}_{(67)} \mathrm{SO}_{3_{(20)}^{-}} \mathrm{PEG}_{(13)}$} $50 \mathrm{mg}$ of $\mathrm{PHO}_{(67)} \mathrm{U}_{(13)} \mathrm{SO}_{3^{-}(20)}$ were dissolved in DMSO at a concentration of $16.7 \mathrm{~g} / \mathrm{L}$ before adding 3 eq (for copolymer containing $\mathrm{PEG}_{(6)}$ ) or 8 eq (for copolymer containing $\mathrm{PEG}_{(13)}$ ) of $\mathrm{PEG} / \mathrm{C}=\mathrm{C}$ and 0.2 eq of $\mathrm{DMPA} / \mathrm{C}=\mathrm{C}$. The mixture was then irradiated during $30 \mathrm{~min}$ at a 
distance of $11 \mathrm{~cm}$ prior purification. Next, copolymer was diluted at $2 \mathrm{~g} / \mathrm{L}$ in DMSO before dialysis against $2 \mathrm{~L}$ of water in 6-8 KDa MWCO membrane during 3 days with 4 water changes per day, followed by freeze-drying. Manipulation was repeated 4 times until maximal elimination of excess PEG (yields of 90 and 94\%, respectively).

\subsection{Characterization}

${ }^{1} \mathrm{H}$ NMR spectra were recorded in $\mathrm{CDCl}_{3}$ or DMSO-d6 on a Bruker AV400 MHz. Size exclusion chromatography (SEC) experiments were determined in chloroform for PHOU using Shimadzu LC-10AD pump with two Shodex GPC K-805L columns (5 $\mu$ m Mixte-C) or in $\mathrm{LiNO}_{3}{ }^{-} 0.5 \mathrm{M}$ solution for copolymers using two PL aquagel-OH 40-30 columns ( $8 \mu \mathrm{m}$ MixteC), both at a concentration of $10 \mathrm{mg} / \mathrm{mL}$. A Wyatt Technology Optilab Rex interferometric refractometer was used as detector, and low polydispersity index polystyrene standards $\left(3 \times 10^{4}\right.$ $-2 \times 10^{6} \mathrm{~g} / \mathrm{mol}$ ) for PHOU analysis, or PEO standards (polyethylene oxide, $106-4.6 \times 10^{4} \mathrm{~g} / \mathrm{mol}$ ) for copolymers measurements, were used to calibrate the system. Differential scanning calorimetry (DSC) measurements were performed on a Perkin Elmer Diamond DSC apparatus. The following protocol was used for each sample: heating from -60 to $+200{ }^{\circ} \mathrm{C}$ at $10{ }^{\circ} \mathrm{C} / \mathrm{min}$, cooling to $-60{ }^{\circ} \mathrm{C}$ at $200{ }^{\circ} \mathrm{C} / \mathrm{min}$, hold $5 \mathrm{~min}$ and heat again to $200{ }^{\circ} \mathrm{C}$ at $10{ }^{\circ} \mathrm{C} / \mathrm{min}$. Transmittance measurements were performed on a Cary50 Bio Varian UV-Visible spectrophotometer controlled by Cary Win UV software. The acquisition was performed from 250 to $800 \mathrm{~nm}$. A $1 \mathrm{~g} . \mathrm{L}^{-1}$ solution of $\mathrm{PHO}_{(67)} \mathrm{U}_{(7)} \mathrm{SO}_{3_{(20)}}{ }^{-} \mathrm{PEG}_{(6)}$ in ultrapure water was used to evaluate the solubility properties of the copolymer. The transmittance of this solution was measured using ultrapure water as reference for the $100 \%$ of transmittance.

\subsection{Preparation of MOF-PHA nanoparticles}

MIL-100(Fe) iron-carboxylate nanoMOF were synthesized by microwave assisted hydrothermal reaction as previously described. ${ }^{38,43} 1 \mathrm{mg}(40 \mu \mathrm{L})$ of MOF was modified by impregnation with $\mathrm{PHO}_{(67)} \mathrm{U}_{(7)} \mathrm{SO}_{3^{-}(20)} \mathrm{PEG}_{(6)}$ or $\mathrm{PHO}_{(67)} \mathrm{SO}_{3^{-}(20)} \mathrm{PEG}_{(13)}$ (from 17 to $83 \%$ (w/w)) in a final MilliQ water volume of $500 \mu \mathrm{L}$ (MOF final concentration $2 \mathrm{mg} / \mathrm{mL}$ ) under gentle rotative agitation for $1 \mathrm{~h}$ at room temperature in the dark.

\subsection{Characterization by STEM-EDX and TEM-EDX}

PHA-MOF nanoparticles size and surface charge were measured by dynamic light scattering (DLS) and zeta potential (ZP) on a Malvern Zetasizer Nano ZS. PHA-MOF nanoparticles 
morphology was investigated by transmission electron microscopy (TEM) on a JEOL-2100F microscope operating at $200 \mathrm{KV}$. Chemical composition was investigated with a FEI TECNAI G2 F20 equipped with scanning TEM (STEM) device fitted to high angle annular dark field imaging (HAADF), energy dispersive X-ray spectrometer (EDX) and electron energy-loss spectrometer (EELS). Chemical composition was also performed with a Merlin (Carl Zeiss) equipped with an EDX Advanced SDD X-Max detector (Oxford Instruments).

\subsection{Cell culture}

Murine macrophages $\mathrm{J} 774$.A1 adherent cells were grown at $37^{\circ} \mathrm{C}$ under humidified atmosphere with $5 \% \mathrm{CO}_{2}$ in Dulbecco's Modified Eagle Medium (DMEM) GlutaMAX ${ }^{\mathrm{TM}}$ supplemented with $10 \%$ inactivated fetal bovine serum, penicillin $\mathrm{G}(100 \mathrm{U} / \mathrm{mL})$ and streptomycin $(0.1$ $\mathrm{mg} / \mathrm{mL}$ ). During experiments, medium was exchanged three times per week.

\subsection{Cytotoxicity assay} Into 96 well plate, J774.A1 were seeded at 20,000 cells/well and then 25, 50, 100, 200 or 400 $\mu \mathrm{g} / \mathrm{mL}$ of uncoated MOF, copolymers of PHA grafted with 6 or 13\% of PEG and MOF-PHA nanoparticles were added following the manufacturer's protocols (LDH cytotoxicity assay, Roche). After $24 \mathrm{~h}$ incubation at $37^{\circ} \mathrm{C}$, absorbance was measured with a Clariostar microplate reader (excitation at $490 \mathrm{~nm}$ and emission at $680 \mathrm{~nm}$ ). As a positive control, cells were exposed to medium containing sterile MilliQ water while untreated murine macrophages served as negative control.

\subsection{Cell proliferation assay}

Into 96 wells plate, J774.A1 were seeded at 5,000 cells/well and then 25,50 or $100 \mu \mathrm{g} / \mathrm{mL}$ of uncoated MOF, copolymers of PHA grafted with 6 or $13 \%$ of PEG and MOF-PHA nanoparticles were added following the manufacturer's protocols (RealTime-Glo ${ }^{\mathrm{TM}}$ MTT Cell Viability Assay kit, Promega). After $72 \mathrm{~h}$ incubation at $37{ }^{\circ} \mathrm{C}$, bioluminescence intensity was measured every day with a Glomax microplate reader. As a negative control, cells were exposed to medium containing sterile MilliQ water while untreated murine macrophages served as positive control.

\section{RESULTS AND DISCUSSION}




\subsection{Preparation and characterization of poly(3-hydroxyalkanoate) sulfonate grafted with} PEG

Poly(3-hydroxyoctanoate-co-3-hydroxyundecenoate) $\mathrm{PHO}_{(67)} \mathrm{U}_{(33)}$ is a hydrophobic polyester composed of long alkyl side chains and lateral alkene groups. The interest in preparing PHAbased copolymers that are both covalently grafted with PEG and sulfonate functions is twofold. It allows both to bind it to the nano-MOF surface by ionic interactions and to avoid the aggregation of nanoparticles due to hydrophilic PEG grafts whose modify the hydrodynamic volume of particles. These particles also became less detectable by immune system cells. First, sulfonate groups $\left(\mathrm{SO}_{3}{ }^{-}\right)$were grafted to the terminal double bonds of the $\mathrm{PHO}_{(67)} \mathrm{U}_{(33)}$, not only to provide an amphiphilic character to the material, ${ }^{32}$ but also to induce non-covalent binding of $\mathrm{SO}_{3}{ }^{-}$ions to $\mathrm{Fe}^{3+}$ ions that are present on the surface of MOF-type nanoparticles, by simple impregnation as shown in Figure 1. $\mathrm{PHO}_{(67)} \mathrm{U}_{(33)}$ was characterized by ${ }^{1} \mathrm{H}$ NMR (Figure 2) to determine the percentage of terminal unsaturations by integrating protons corresponding to the $\mathrm{CH}$ peak (2) at $5.1 \mathrm{ppm}$, and the signal relating to the terminal alkene group of side chain (7) at 5.7 ppm. Sodium-3-mercapto-1-ethanesulfonate was grafted under photochemical activation, using from 1 to 5 molar equivalents of sulfonates $\left(\mathrm{SO}_{3}{ }^{-}\right)$. After purification by dialysis, polymers were analyzed by ${ }^{1} \mathrm{H} \mathrm{NMR}$, and signals relating to the two $\mathrm{CH}_{2}$ methylenes $(\mathrm{c}, \mathrm{d})$, characteristic of sulfonate groups, appear at $2.66 \mathrm{ppm}$, indicating the success of the grafting. The conversion percentages of the terminal double bonds to $\mathrm{SO}_{3}{ }^{-}$were calculated by comparing the integrations of the protons corresponding to the $\mathrm{CH}$ peak (2) of the $\mathrm{PHO}_{(67)} \mathrm{U}_{(33)}$ structure at $5.1 \mathrm{ppm}$, with respect to the signal of terminal unsaturation HU side chain (7) at $5.7 \mathrm{ppm}$ (Figure 3). The results obtained indicate a non-linear relationship between the conversion rate of double bonds of $\mathrm{PHO}_{(67)} \mathrm{U}_{(33)}$ and the concentrations of sodium-3-mercapto-1-ethanesulfonate (RSH) used. The copolymers were obtained with yields between 86 and 95\%, reflecting the effectiveness of the grafting method. In order to maintain a sufficient number of unsaturations for the subsequent grafting of PEG methyl ether thiol, $\mathrm{PHO}_{(67)} \mathrm{U}_{(13)} \mathrm{SO}_{3^{-}(20)}$ is therefore obtained by using 1.2 equivalents $\mathrm{RSH} / \mathrm{C}=\mathrm{C}$. The copolymer is not soluble in water, THF or even $\mathrm{CHCl}_{3}$ as it is traditionally the case with native PHA whereas complete solubilization is observed in DMSO.

In a second step PEG methyl ether thiol was grafted using the photoinduced thiol-ene reaction. Low molecular weight PEG is a highly polar and water-soluble polymer, widely used in pharmaceuticals for its biocompatibility and stealth properties. Two different ratios of PEG methyl ether thiol ( 3 and 8 molar equivalents of PEG per mole of PHOU unsaturation) were used (Figure 4). Two peaks are observed at 3.5 and $3.2 \mathrm{ppm}$, corresponding to the $\mathrm{CH}_{2}(\mathrm{e})$ and 
$\mathrm{CH}_{3}$ (f) methyl terminal groups of the PEG confirming the success of the grafting. The grafting percentages were calculated from the integrations of the signals of the PHOU at $5.1 \mathrm{ppm}$, and the signal relating to the terminal unsaturations of the HU pattern side chain (7) at $5.7 \mathrm{ppm}$. Two PEG ratios were found attesting the synthesis of copolymers of $\mathrm{PHO}_{(67)} \mathrm{U}_{(7)} \mathrm{SO}_{3^{-}{ }_{(20)}} \mathrm{PEG}_{(6)}$ with the use of 3 eq $\mathrm{PEG} / \mathrm{C}=\mathrm{C}$, and $\mathrm{PHO}_{(67)} \mathrm{SO}_{3{ }^{-}(20)} \mathrm{PEG}_{(13)}$ in presence of 8 eq $\mathrm{PEG} / \mathrm{C}=\mathrm{C}$ with a yield of $92 \%$. The turbidity measurement showed a colorless solution at $550 \mathrm{~nm}$ indicating absence of micelles or aggregates attesting of a total solubilization of $\mathrm{HO}_{(67)} \mathrm{U}_{(7)} \mathrm{SO}_{3^{-}{ }_{(20)}} \mathrm{PEG}_{(6)}$ and $\mathrm{PHO}_{(67)} \mathrm{SO}_{3^{-}(20)} \mathrm{PEG}_{(13)}$ in water (Figure 5). PEG methyl ether thiol, $\mathrm{PHO}_{(67)} \mathrm{U}_{(33)}$ and the copolymers of $\mathrm{PHO}_{(67)} \mathrm{U}_{(7)} \mathrm{SO}_{3^{-}(20)} \mathrm{PEG}_{(6)}$ and $\mathrm{PHO}_{(67)} \mathrm{SO}_{3^{-}(20)} \mathrm{PEG}_{(13)}$ were analyzed by SEC (Table 1). PEG methyl ether thiol has a molecular weight of 1,700 g.mol $^{-1}$ and native $\mathrm{PHO}_{(67)} \mathrm{U}_{(33)}$ has a molar mass of 40,000 g. $\mathrm{mol}^{-1}$ with a polydispersity index of 1.7 , a value generally obtained is the case of natural PHAs. The copolymers of $\mathrm{PHO}_{(67)} \mathrm{U}_{(7)} \mathrm{SO}_{3^{-}(20)} \mathrm{PEG}_{(6)}$ and $\mathrm{PHO}_{(67)} \mathrm{SO}_{3^{-}(20)} \mathrm{PEG}_{(13)}$ have molar masses of 24,000 and 29,500 g. $\mathrm{mol}^{-1}$ respectively. The difference of molar masses are explained by the difference of the chain conformations of $\mathrm{PHO}_{(67)} \mathrm{U}_{(33)}$ and the grafted copolymers. Furthermore, the molar masses are expressed in PS equivalent in the case of $\mathrm{PHO}_{(67)} \mathrm{U}_{(33)}$ and in PEG equivalents in the case of grafted copolymers Consequently, the difference between natural $\mathrm{PHO}_{(67)} \mathrm{U}_{(33)}$ and grafted copolymers are due to the difference of their solubility instead of a potential degradation of macromolecular chains. It has been previously shown that thiol-ene reactions proceeded without any chain scission of unsaturated PHAs. ${ }^{20}$ DSC measurements confirm the semi-crystalline structure of the copolymers (Figure 5). However, the values of the melting enthalpies of copolymers are lower than that of the free PEG, thus showing some inhibitory action of PHA on the crystallization of PEG, a phenomenon already observed in similar work carried out by Babinot et al. ${ }^{20}$ Similarly, the presence of PEG polymers prevents the crystallization of PHA.

\subsection{Characterization of nano-hybrid MOF by electron microscopy and energy dispersive} X-ray spectrometer

Transmission electron microscopy (TEM) images were performed on the native MOF and the MOF-PHA hybrid nanoparticles, MOF-PHO $\mathrm{PH}_{(67)} \mathrm{U}_{(7)} \mathrm{SO}_{3^{-}(20)} \mathrm{PEG}_{(6)}$ and $\mathrm{MOF}-\mathrm{PHO}_{(67)} \mathrm{SO}_{3^{-}}$ ${ }_{(20)} \mathrm{PEG}_{(13)}$. The overlay of MOF-type nanoparticles by functionalized PHA does not impact either the morphology or the size of the nanoparticles since average diameters between 250 and $300 \mathrm{~nm}$ have been measured (Figure 6). The proportions of $\mathrm{C}, \mathrm{O}, \mathrm{Fe}$ and $\mathrm{S}$ atoms were quantified by STEM-EDX and SEM-EDX techniques. The presence of sulphur atoms, 
271 characteristic of the presence of functionalized PHA at the surface of the nanoMOF, was detected on the surface of both types of hybrid nanoparticles at equivalent atomic percentages from both techniques $(0.8 \%)$ (Table 2$)$. The average $\mathrm{S} / \mathrm{Fe}$ ratios were calculated in a very similar way using the two STEM-EDX and SEM-EDX techniques (0.13-0.16), corresponding to one sulphur atom as a marker for functionalized copolymers for eight iron atoms belonging to MOF. These results confirm the adsorption of functionalized PHA copolymers on the surface of MOFtype nanoparticles. The increase in the $\mathrm{C} / \mathrm{Fe}$ ratio is all the more significant when the percentage of PEG is high within copolymers, corresponding to rates of 11.6, 12.9 and 15.1 (STEM-EDX), and 8.5, 10 and 11.1 (SEM-EDX), before and after coating nanoMOFs with $\mathrm{PHO}_{(67)} \mathrm{U}_{(7)} \mathrm{SO}_{3}{ }^{-}$ ${ }_{(20)} \mathrm{PEG}_{(6)}$ or $\mathrm{PHO}_{(67)} \mathrm{SO}_{3{ }^{-}(20)} \mathrm{PEG}_{(13)}$ copolymers.

\subsection{Stability of nano-hybrid MOF in aqueous medium}

The two copolymers previously described were used to coat MOF nanoparticles to develop stable porous MOF-PHA hybrid systems (Figure 1). The zeta potential measurements showed a highly electropositive charge of $+23 \mathrm{mV}$ for native MOF nanoparticles, and electronegative charges of $-41 \mathrm{mV}$ for $\mathrm{PHO}_{(67)} \mathrm{U}_{(7)} \mathrm{SO}_{3^{-}(20)} \mathrm{PEG}_{(6)}$ and $-24 \mathrm{mV}$ for $\mathrm{PHO}_{(67)} \mathrm{SO}_{3^{-}(20)} \mathrm{PEG}_{(13)}$. Different concentrations of $\mathrm{PHO}_{(67)} \mathrm{U}_{(7)} \mathrm{SO}_{3^{-}(20)} \mathrm{PEG}_{(6)}$ and $\mathrm{PHO}_{(67)} \mathrm{SO}_{3^{-}(20)} \mathrm{PEG}_{(13)}$ from 0.4 to $10 \mathrm{~g} / \mathrm{L}$ were placed in ultrapure water in presence of $2 \mathrm{~g} / \mathrm{L}$ MOF. An instantaneous decrease in zeta potential measured on the surface of MOF nanoparticles after contact with $1 \mathrm{~g} / \mathrm{L}$ copolymers was observed (Figure 7) thus confirming the coverage of MOF by functionalized PHA copolymers. The diameter of the nanoparticles were measured by DLS (Figure 8). The dispersion in water of the nanoMOF native or coated with 0.4 or $1 \mathrm{~g} / \mathrm{L} \mathrm{PHA}$ was not stable and the particles agglomerated in 1 hour. Incubation of nanoMOF in the presence of low $(0.4$ or 1 $\mathrm{g} / \mathrm{L}$ ) concentrations of functionalized PHA was not sufficient to generate optimal recovery to ensure the stability of nanoparticles over time. These results are in agreement with previous studies showing the instability of the same nanoMOFs in aqueous media. ${ }^{46}$. In contrast, the use of $2 \mathrm{~g} / \mathrm{L}$ of copolymers of $\mathrm{PHO}_{(67)} \mathrm{U}_{(7)} \mathrm{SO}_{3^{-}(20)} \mathrm{PEG}_{(6)}$ and $\mathrm{PHO}_{(67)} \mathrm{SO}_{3^{-}(20)} \mathrm{PEG}_{(13)}$ successfully allowed the development of stable hybrid nanoparticles. While MOF-PHO $\mathrm{PH}_{(67)} \mathrm{SO}_{3_{(20)}{ }^{-}} \mathrm{PEG}_{(13)}$ nanoparticles diameters remained stable for more than three days, MOF- $\mathrm{PHO}_{(67)} \mathrm{U}_{(7)} \mathrm{SO}_{3}{ }^{-}$ ${ }_{(20)} \mathrm{PEG}_{(6)}$ diameters measured by DLS were heterogeneous, greater than $350 \mathrm{~nm}$ during the first 48 hours, higher than the expected $270-300 \mathrm{~nm}$. These data again reflect some aggregation of particles possibly by a bridging effect and, in fact, insufficient coverage of PHAs on the surface of MOFs to ensure steric stabilization. The best results in terms of stability in water were obtained with the use of $4 \mathrm{~g} / \mathrm{L}$ PHA regardless of the copolymer $\left(\mathrm{PHO}_{(67)} \mathrm{U}_{(7)} \mathrm{SO}_{3^{-}(20)}{ }^{-} \mathrm{PEG}_{(6)}\right.$ or 
$305 \mathrm{PHO}_{(67)} \mathrm{SO}_{3(20)}^{-} \mathrm{PEG}_{(13)}$ ) over a 72-hour period. Complementary experiments showed that MOF$306 \mathrm{PHO}_{(67)} \mathrm{SO}_{3{ }^{-}(20)} \mathrm{PEG}_{(13)}$ nanoparticles remained stable for more than 6 hours in PBS.

\subsection{Biological tests}

309 Grafted functionalized PHAs by using thiol-ene reaction did not demonstrate any significant 310 toxicity on the basis of viability assays on two different cell lines, mouse fibroblast cells 311 (NIH/3T3) and murine macrophage cells (J774.A1). ${ }^{55}$ In this context, the possible in vitro toxic 312 effects of the MOF-PHA hybrid nanoparticles were determined using the LDH cytotoxicity. 313 The murine phagocytic cells J774.A1 were selected for these studies because they are model 314 cells, commonly used in cell biology and immunology, genetically stable and particularly 315 reactive in the presence of pathogens. ${ }^{56}$ At concentrations lower than $50 \mu \mathrm{g} / \mathrm{mL}$ functionalized 316 PHA copolymers do not appear to generate toxic reaction against J774.A1 macrophages, as cell 317 viabilities close to 100\% were observed (Figure 9). However, at concentrations in the range of $318 \quad 100-200 \mu \mathrm{g} / \mathrm{mL}$, a proliferative effect was observed. This trend could be explained by processes such as immune stimulation of the J774.A1 macrophages, which will have to be further investigated. Finally, the use of hybrid nanoparticles $M O F-\mathrm{PHO}_{(67)} \mathrm{U}_{(7)} \mathrm{SO}_{3^{-}(20)} \mathrm{PEG}_{(6)}$ and MOF-PHO ${ }_{(67)} \mathrm{SO}_{3{ }^{-}(20)} \mathrm{PEG}_{(13)}$ at concentrations between 25 and $100 \mu \mathrm{g} / \mathrm{mL}$ does not cause any significant reaction from J774.A1 cells, since percentages of cell viability close to $100 \%$ were observed. However, the administration of hybrid nanoparticles at higher doses results in a decrease macrophage viability, ranging from 70 to $85 \%$ at $200 \mu \mathrm{g} / \mathrm{mL}$. Thus, in view of further in vitro investigations, the nanoMOF concentrations were limited to $100 \mu \mathrm{g} / \mathrm{mL}$. The proliferation of macrophage-type immune cells is a marker of phagocytic activation, a step preceding the inflammatory response. ${ }^{57-58}$ The division of J774.A1 cells at 25, 50 or $100 \mu \mathrm{g} / \mathrm{mL}$ of functionalized PHAs and native or hybrid MOF-type nanoparticles was measured over $42 \mathrm{~h}$. The cell proliferation experiments were conducted using the RealTime Glo kit which allows the quantification of living cells from the bioluminescence emitted from the luciferase substrate, reduced by the enzymatic activity of any viable cell. Results obtained after $42 \mathrm{~h}$ incubation of J774.A1 macrophages with 25,50 or $100 \mu \mathrm{g} / \mathrm{mL}$ of bare or hybrid PHA copolymers or nanoMOFs are shown in Figure 10. These results demonstrate cell proliferation of the J774.A1 macrophages in contact with iron-based MOFs and further studies will be necessary to decipher the involved mechanism. However these preliminary results showed that materials were not cytotoxic. 


\section{CONCLUSION}

An efficient and reproducible method for the synthesis of copolymers of water-soluble $\mathrm{PHO}_{(67)} \mathrm{U}_{(7)} \mathrm{SO}_{3^{-}{ }_{(20)}} \mathrm{PEG}_{(6)}$ and $\mathrm{PHO}_{(67)} \mathrm{SO}_{3^{-}{ }_{(20)}} \mathrm{PEG}_{(13)}$ has been developed by two successive photoactivated thiol-ene reactions. These two copolymers will be used for the coating of MOFtype nanoparticles. The graft copolymers based on unsaturated PHAs have been heterofunctionalized with on one hand the polar $\mathrm{SO}_{3}{ }^{-}$sulfonate groups to promote ionic interactions with nanoMOF and on the other hand with PEG moieties to improve hydrophilicity. The molar composition of the copolymer is strictly controlled thanks to the efficiency of the thiol-ene reaction. The presence of sulphur detected by the STEM technique coupled with EDX attests to the effective coating of the MOF surface by the functionalized copolymers. The presence of PEG aims on the one hand to increase the stability of the system in a physiological environment and on the other hand to escape the phagocytic cells of the immune system. Moreover, nano-hybrid MOF based on PHA copolymers do not cause a significant toxicity reaction against J774.A1 macrophages. With further studies, the hybrid nanoparticles MOF$\mathrm{PHO}_{(67)} \mathrm{U}_{(7)} \mathrm{SO}_{3^{-}(20)} \mathrm{PEG}_{(6)}$ and $\mathrm{MOF}-\mathrm{PHO}_{(67)} \mathrm{SO}_{3^{-}(20)} \mathrm{PEG}_{(13)}$ with a diameter close to $300 \mathrm{~nm}$ that are stable for at least $6 \mathrm{~h}$ in a buffered physiological environment, would constitute a new generation of biocompatible therapeutic nanovectors as innovative drug delivery system.

\section{AUTHOR INFORMATION}

\section{Acknowledgments}

The Authors would like to thank Eric LEROY and Remy PIRES for their technical assistance with the SEM-STEM EDX, Annick JACQ for the access to the ClarioSTAR system and Laurent MICHELY for his technical experiment. We are grateful to the financial support of IFREMER and Region Bretagne, France.

Corresponding author

Valérie LANGLOIS

E mail: langlois@icmpe.cnrs.fr 


\section{References}

368 (1) Anderson, A. J.; Dawes, E. A. Occurrence, metabolism, metabolic role, and industrial uses 369 of bacterial polyhydroxyalkanoates. Microbiol. Rev. 1990, 54 (4), 450-472.

370 (2) Steinbüchel, A.; Valentin, H. E. Diversity of bacterial polyhydroxyalkanoic acids. FEMS 371 Microbiol. Lett. 1995, 128 (3), 219-228.

(3) Zinn, M.; Witholt, B.; Egli, T. Occurrence, synthesis and medical application of bacterial polyhydroxyalkanoate. Adv. Drug Deliv. Rev. 2001, 53 (1), 5-21.

(4) Bedian, L.; Villalba-Rodríguez, A. M.; Hernández-Vargas, G.; Parra-Saldivar, R.; Iqbal,

H. M. N. Bio-based materials with novel characteristics for tissue engineering applications - a review. Int. J. Biol. Macromol. 2017, 98, 837-846.

(5) Shrivastav, A.; Kim, H.-Y.; Kim, Y.-R. Advances in the applications of polyhydroxyalkanoate nanoparticles for novel drug delivery system. BioMed Res. Int. 2013, 379 $2013,1-12$.

(6) Li, Z.; Loh, X. J. Recent advances of using polyhydroxyalkanoate-based Nanovehicles as 381 therapeutic delivery carriers. Wiley Interdiscip. Rev. Nanomed. Nanobiotechnol. 2016, 9 (3), 382 e1429.

(7) Zhang, J.; Shishatskaya, E. I.; Volova, T. G.; da Silva, L. F.; Chen, G.-Q. Polyhydroxyalkanoates (PHA) for therapeutic applications. Mater. Sci. Eng. C 2018, 86, 144385 150.

(8) Nigmatullin, R.; Thomas, P.; Lukasiewicz, B.; Puthussery, H.; Roy, I. Polyhydroxyalkanoates, a family of natural polymers, and their applications in drug delivery. J. Chem. Technol. Biotechnol. 2015, 90 (7), 1209-1221.

(9) Martin, D. P.; Williams, S. F. Medical applications of poly-4-hydroxybutyrate: a strong 390 flexible absorbable biomaterial. Biochem. Eng. J. 2003, 16 (2), 97-105.

(10) Philip, S.; Keshavarz, T.; Roy, I. Polyhydroxyalkanoates: biodegradable polymers with a 392 range of applications. J. Chem. Technol. Biotechnol. 2007, 82 (3), 233-247.

(11) Ramier, J.; Bouderlique, T.; Stoilova, O.; Manolova, N.; Rashkov, I.; Langlois, V.; hydroxybutyrate) nanofibers and electrosprayed hydroxyapatite nanoparticles for bone tissue engineering applications. Mater. Sci. Eng. C 2014, 38, 161-169.

398 Functionalized oligoesters from poly(3-hydroxyalkanoate)s containing reactive end group for 
399 click chemistry: application to novel copolymer synthesis with poly(2-methyl-2-oxazoline).

400

401

402

403

404

405

406

407

408

409

410

411

412

413

414

415

416

417

418

419

420

421

422

423

424

425

426

427

428

429

430

431

432 React. Funct. Polym. 2012, 72 (2), 160-167.

(13) Alcantar, N. A.; Aydil, E. S.; Israelachvili, J. N. Polyethylene glycol-coated biocompatible surfaces. J. Biomed. Mater. Res. 2000, 51 (3), 343-351.

(14) Lutz, J.-F. Polymerization of oligo(ethylene glycol) (meth)acrylates: toward new generations of smart biocompatible materials. J. Polym. Sci. Part Polym. Chem. 2008, 46 (11), $3459-3470$.

(15) Zalipsky, S. Synthesis of an end-froup functionalized polyethylene glycol-lipid conjugate for preparation of polymer-grafted liposomes. Bioconjug. Chem. 1993, 4, 296-299.

(16) He, X.; Li, L.; Su, H.; Zhou, D.; Song, H.; Wang, L.; Jiang, X. Poly(ethylene glycol)block-poly(E-caprolactone)-and phospholipid-based stealth nanoparticles with enhanced therapeutic efficacy on murine breast cancer by improved intracellular drug delivery. Int. J. Nanomedicine 2015, 10, 1791-1804.

(17) Lu, X.-Y.; Li, M.-C.; Zhu, X.-L.; Fan, F.; Wang, L.-L.; Ma, J.-G. Microbial synthesized biodegradable PHBHHxPEG hybrid copolymer as an efficient intracellular delivery nanocarrier for kinase inhibitor. BMC Biotechnol. 2014, 14 (1), 1.

(18) Shah, M.; Ullah, N.; Choi, M. H.; Kim, M. O.; Yoon, S. C. Amorphous amphiphilic P(3HV-Co-4HB)-b-MPEG block copolymer synthesized from bacterial copolyester via melt transesterification: nanoparticle preparation, cisplatin-loading for cancer therapy and in vitro evaluation. Eur. J. Pharm. Biopharm. 2012, 80 (3), 518-527.

(19) Babinot, J.; Renard, E.; Langlois, V. Preparation of clickable poly(3-hydroxyalkanoate) (PHA): application to poly(ethylene glycol) (PEG) graft copolymers synthesis. Macromol. Rapid Commun. 2010, 31 (7), 619-624.

(20) Babinot, J.; Renard, E.; Langlois, V. Controlled synthesis of well defined poly(3hydroxyalkanoate)s-based amphiphilic diblock copolymers using click chemistry. Macromol. Chem. Phys. 2011, 212 (3), 278-285.

(21) Babinot, J.; Guigner, J.-M.; Renard, E.; Langlois, V. A micellization study of medium chain length poly(3-hydroxyalkanoate)-based amphiphilic diblock copolymers. J. Colloid Interface Sci. 2012, 375 (1), 88-93.

(22) Babinot, J.; Guigner, J.-M.; Renard, E.; Langlois, V. Poly(3-hydroxyalkanoate)-derived amphiphilic graft copolymers for the design of polymersomes. Chem. Commun. 2012, 48 (43), 5364-5366.

(23) Hazer, D. B.; Kılıçay, E.; Hazer, B. Poly(3-hydroxyalkanoate)s: diversification and biomedical applications: a state of the art review. Mater. Sci. Eng. C 2012, 32 (4), 637-647. 
433 434 435 436 437 438 439 440 441 442 443 444 445 446 447 448 449 450 451 452 453 454 455 456 457 458 459 460 461 462 463 464 465

(24) Hazer, B.; Steinbüchel, A. Increased diversification of polyhydroxyalkanoates by modification reactions for industrial and medical applications. Appl. Microbiol. Biotechnol. 2007, $74(1), 1-12$.

(25) Winnacker, M.; Rieger, B. Copolymers of polyhydroxyalkanoates and polyethylene glycols: recent advancements with biological and medical significance. Polym. Int. 2017, 66 (4), 497-503.

(26) Ravenelle, F.; Marchessault, R. H. One-step synthesis of amphiphilic diblock copolymers from bacterial poly([R]-3-hydroxybutyric acid). Biomacromolecules 2002, 3 (5), 1057-1064.

(27) Ravenelle, F.; Marchessault, R. H. Self-assembly of Poly([R]-3-hydroxybutyric acid)block-poly(ethylene glycol) diblock copolymers. Biomacromolecules 2003, 4 (3), 856-858.

(28) Li, J.; Ni, X.P.; Li, X.; Tan, N.K.; Lim, C.T.; Ramakrishna, S.; Leong, K.W. Micellization phenomena of biodegradable amphiphilic triblock copolymers consisting of poly $(\beta-$ hydroxyalkanoic acid) and poly(ethylene oxide). Langmuir 2005, 21 (19) 8681-8685.

(29) Kurth, N.; Renard, E.; Brachet, F.; Robic, D.; Guerin, P.; Bourbouze, R. Poly(3hydroxyoctanoate) containing pendant carboxylic groups for the preparation of nanoparticles aimed at drug transport and release. Polymer 2002, 43, 1095-1101.

(30) Sparks, J.; Scholz, C. Synthesis and characterization of a cationic poly( $\beta$ hydroxyalkanoate). Biomacromolecules 2008, 9 (8), 2091-2096.

(31) Yu, L.-P.; Zhang, X.; Wei, D.-X.; Wu, Q.; Jiang, X.-R.; Chen, G.-Q. Highly efficient fluorescent material based on rare-earth-modified polyhydroxyalkanoates. Biomacromolecules 2019, 9 .

(32) Modjinou, T.; Lemechko, P.; Babinot, J.; Versace, D.-L.; Langlois, V.; Renard, E. Poly(3hydroxyalkanoate) sulfonate: from nanoparticles toward water soluble polyesters. Eur. Polym. J. 2015, 68, 471-479.

(33) Pavon-Djavid, G.; Gamble, L. J.; Ciobanu, M.; Gueguen, V.; Castner, D. G.; Migonney, V. Bioactive poly(ethylene terephthalate) fibers and fabrics: grafting, chemical characterization, and biological assessment. Biomacromolecules 2007, 8 (11), 3317-3325.

(34) Hany, R.; Bohlen, C.; Geiger, T.; Hartmann, R.; Kawada, J.; Schmid, M.; Zinn M.; Marchessault, R. H. Chemical synthesis of crystalline comb polymers from olefinic mediumchain-length poly[3-hydroxyalkanoates]. Macromolecules 2004, 32 (2), 385-389.

(35) Li, H.; Eddaoudi, M.; O’Keeffe, M.; Yaghi, O. M. Design and synthesis of an exceptionally stable and highly porous metal-organic framework. Nature 1999, 402 (6759), $276-279$. 
(36) Huxford, R. C.; Della Rocca, J.; Lin, W. Metal-organic frameworks as potential drug carriers. Curr. Opin. Chem. Biol. 2010, 14 (2), 262-268.

(37) He, C.; Liu, D.; Lin, W. Nanomedicine applications of hybrid nanomaterials built from metal-ligand coordination bonds: nanoscale metal-organic frameworks and nanoscale coordination polymers. Chem. Rev. 2015, 115 (19), 11079-11108.

(38) Agostoni, V.; Chalati, T.; Horcajada, P.; Willaime, H.; Anand, R.; Semiramoth, N.; Baati, T.; Hall, S.; Maurin, G.; Chacun, H. Towards an improved anti-HIV activity of NRTI via metalorganic frameworks nanoparticles. Adv. Healthc. Mater. 2013, 2 (12), 1630-1637.

(39) Chalati, T.; Horcajada, P.; Couvreur, P.; Serre, C.; Ben Yahia, M.; Maurin, G.; Gref, R. Porous metal organic framework nanoparticles to address the challenges related to busulfan encapsulation. Nanomed. 2011, 6 (10), 1683-1695.

(40) Férey, G.; Mellot-Draznieks, C.; Serre, C.; Millange, F.; Dutour, J.; Surblé, S.; Margiolaki, I. A chromium terephthalate-based solid with unusually large pore volumes and surface area. Science 2005, 309 (5743), 2040-2042.

(41) Horcajada, P.; Gref, R.; Baati, T.; Allan, P. K.; Maurin, G.; Couvreur, P.; Férey, G.; Morris, R. E.; Serre, C. Metal-organic frameworks in biomedicine. Chem. Rev. 2012, 112 (2), $1232-1268$.

(42) Horcajada, P.; Chalati, T.; Serre, C.; Gillet, B.; Sebrie, C.; Baati, T.; Eubank, J. F.; Heurtaux, D.; Clayette, P.; Kreuz, C.; Chang, J.S.; Hwang, Y.K.; Marsaud, V; Bories, P.N.; Cynober, L.; Gil, S.; Ferey, G.; Couvreur, P.; Gref, R. Porous metal-organic-framework nanoscale carriers as a potential platform for drug delivery and imaging. Nat. Mater. 2010, 9 (2), 172-178.

(43) Agostoni, V.; Horcajada, P.; Noiray, M.; Malanga, M.; Aykaç, A.; Jicsinszky, L.; VargasBerenguel, A.; Semiramoth, N.; Daoud-Mahammed, S.; Nicolas, V.; Martineau, C.; Taulette, F.; Vigneron, J.; Etcheberry, A.; Serre, C.; Gref, R. A "green" strategy to construct noncovalent, stable and bioactive coatings on porous MOF nanoparticles. Sci. Rep. 2015, 5 (1).

(44) Bellido, E.; Hidalgo, T.; Lozano, M. V.; Guillevic, M.; Simón-Vázquez, R.; Santander-Ortega, M. J.; González-Fernández, Á.; Serre, C.; Alonso, M. J.; Horcajada, P. Heparin-engineered mesoporous iron metal-organic framework nanoparticles: toward stealth drug nanocarriers. Adv. Healthc. Mater. 2015, 4 (8), 1246-1257.

(45) Baati, T.; Njim, L.; Neffati, F.; Kerkeni, A.; Bouttemi, M.; Gref, R.; Najjar, M. F.; Zakhama, A.; Couvreur, P.; Serre, C.; Horcajada, P. In depth analysis of the in vivo toxicity of nanoparticles of porous iron(III) metal-organic frameworks. Chem. Sci. 2013, 4 (4), $1597-$ 1607. 
500 (46) Aykaç, A.; Noiray, M.; Malanga, M.; Agostoni, V.; Casas-Solvas, J. M.; Fenyvesi, É.; 501 Gref, R.; Vargas-Berenguel, A. A non-covalent "click chemistry" strategy to efficiently coat 502 highly porous MOF nanoparticles with a stable polymeric shell. Biochim. Biophys. Acta BBA 503 Gen. Subj. 2017, 1861 (6), 1606-1616.

504

(47) Cai, W.; Gao, H.; Chu, C.; Wang, X.; Wang, J.; Zhang, P.; Lin, G.; Li, W.; Liu, G.; Chen, 505 $\mathrm{X}$. Engineering phototheranostic nanoscale metal-organic frameworks for multimodal 506 imaging-guided cancer therapy. ACS Appl. Mater. Interfaces 2017, 9 (3), 2040-2051.

507 (48) Hidalgo, T.; Giménez-Marqués, M.; Bellido, E.; Avila, J.; Asensio, M. C.; Salles, F.; 508 Lozano, M. V.; Guillevic, M.; Simón-Vázquez, R.; González-Fernández, A.; Serre, C.; Alonso, 509 M. J.; Horcajada, P. Chitosan-coated mesoporous MIL-100(Fe) nanoparticles as improved bio510 compatible oral nanocarriers. Sci. Rep. 2017, 7, 43099.

(49) Liang, X.-X.; Wang, N.; Qu, Y.-L.; Yang, L.-Y.; Wang, Y.-G.; Ouyang, X.-K. Facile 512 preparation of metal-organic framework (MIL-125)/chitosan beads for adsorption of $\mathrm{Pb}(\mathrm{II})$ from aqueous solutions. Molecules 2018, 23 (7), 1524.

514 (50) Wuttke, S.; Braig, S.; Preiß, T.; Zimpel, A.; Sicklinger, J.; Bellomo, C.; O. Rädler, J.; 515 M. Vollmar, A.; Bein, T. MOF nanoparticles coated by lipid bilayers and their uptake by cancer cells. Chem. Commun. 2015, 51 (87), 15752-15755.

(51) Filippousi, M.; Turner, S.; Leus, K.; Siafaka, P. I.; Tseligka, E. D.; Vandichel, M.; Nanaki, S. G.; Vizirianakis, I. S.; Bikiaris, D. N.; Van Der Voort, P. Biocompatible Zr-based nanoscale 519 MOFs coated with modified poly(E-caprolactone) as anticancer drug carriers. Int. J. Pharm. 2016, 509 (1-2), 208-218.

(52) Giménez-Marqués, M.; Bellido, E.; Berthelot, T.; Simón-Yarza, T.; Hidalgo, T.; Simón-Vázquez, R.; González-Fernández, Á.; Avila, J.; Asensio, M. C.; Gref, R.; Couvreur, P.; 523 Serre, C.; Horcajada, P. GraftFast furface engineering to improve MOF nanoparticles furtiveness. Small 2018, $18011900,1-11$.

(53) Rivas, B. L.; Pereira, E. D.; Moreno-Villoslada, I. Water-soluble polymer-metal ion interactions. Prog. Polym. Sci. 2003, 28, 173-208.

527 (54) Yue, J.; Wang, Z. H.; Cromack, K. R.; Epstein, A. J.; MacDiarmid, A. G. Effect of sulfonic 528 acid group on polyaniline backbone. J. Am. Chem. Soc. 1991, 113 (7), 2665-2671.

(55) Babinot, J.; Renard, E.; Le Droumaguet B., ; Guigner, J.-M.; Mura S.; Nicolas J.; 530 Couvreur P.; Langlois, V. Facile Synthesis of Multicompartment Micelles Based on Biocompatible Poly(3-hydroxyalkanoate). Macromol. Rapid Commun. 2012, 34, 362-368.

532 (56) Lam, J.; Herant, M.; Dembo, M.; Heinrich, V. Baseline mechanical characterization of $533 \quad$ J774 macrophages. Biophys. J. 2009, 96 (1), 248-254. 
534 (57) Jenkins, S. J.; Ruckerl, D.; Cook, P. C.; Jones, L. H.; Finkelman, F. D.; Rooijen, N. van; 535 MacDonald, A. S.; Allen, J. E. Local macrophage proliferation, rather than recruitment from 536 the blood, is a signature of TH2 inflammation. Science 2011, 332 (6035), 1284-1288.

537 (58) Rőszer, T. Understanding the mysterious M2 macrophage through activation markers and 538 effector mechanisms. Mediators Inflam. 2015, 816460.

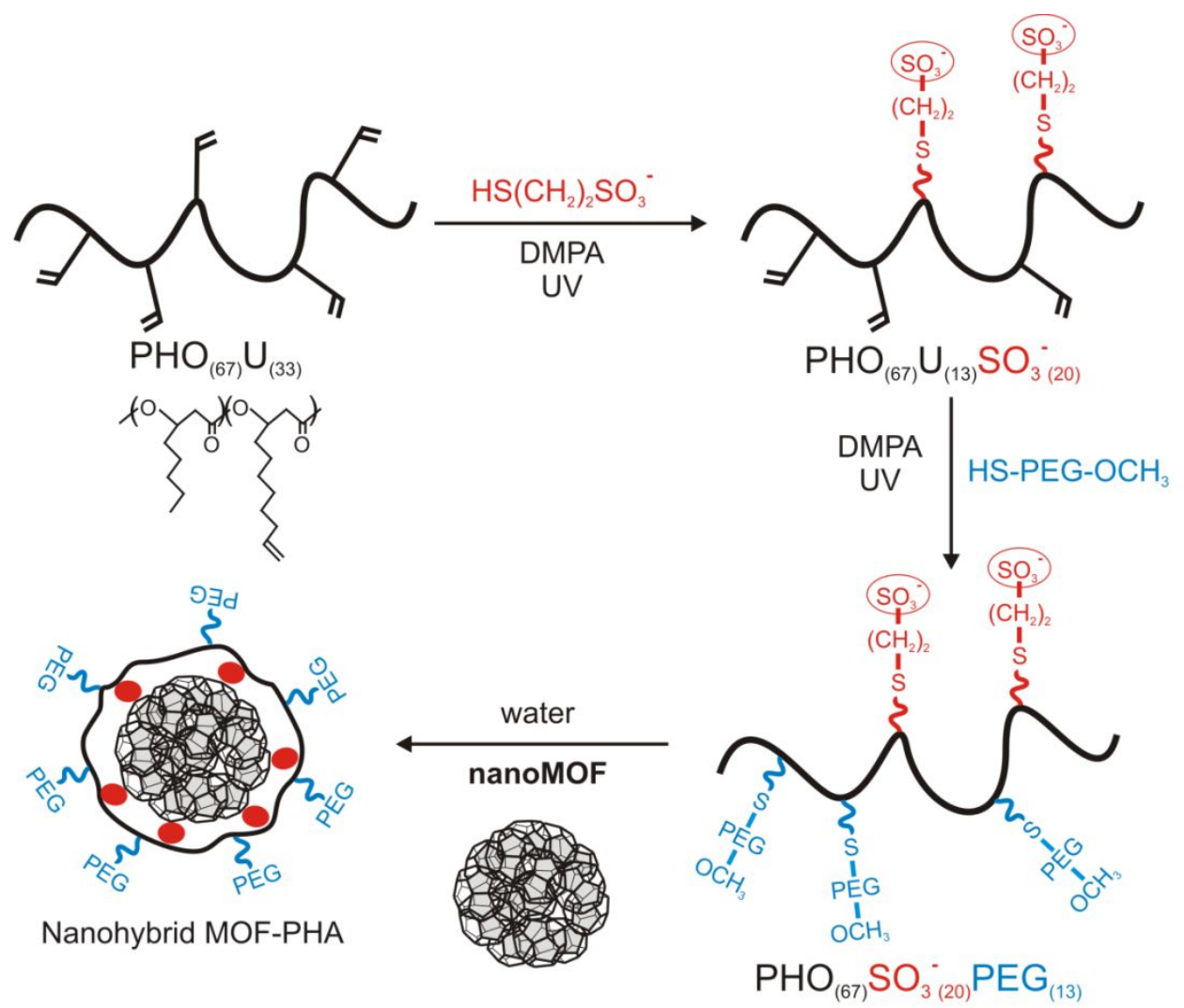

Figure 1. Elaboration of nanohybrid MOF-PHA 
a)

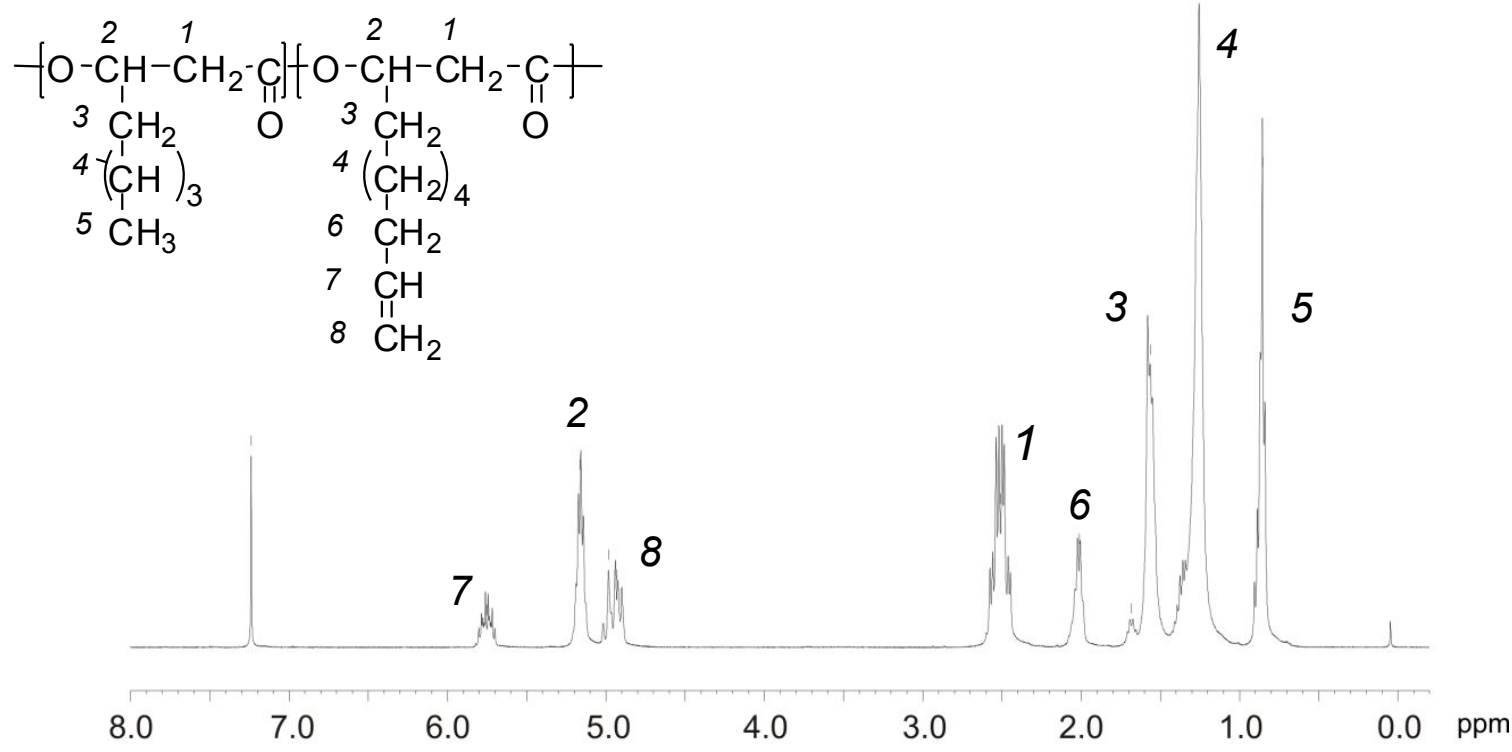

b)

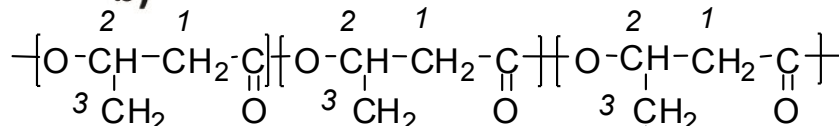

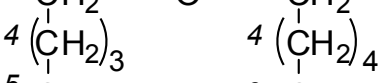

${ }^{5} \mathrm{CH}_{3}$

$6 \stackrel{\mathrm{C}}{\mathrm{C}} \mathrm{H}_{2}$

$7 \mathrm{CH}$

$8 \mathrm{CH}_{2}$

$4\left(\underset{1}{\mathrm{C}} \mathrm{H}_{2}\right)_{4}$

$6 \mathrm{CH}_{2}$

a $\mathrm{C}_{1}^{\mathrm{C}} \mathrm{H}_{2}$

b $\stackrel{\mathrm{I}}{\mathrm{C}} \mathrm{H}_{2}$

S

c $\mathrm{CH}_{2}$

d $\mathrm{CH}_{2}$ $\mathrm{SO}_{3} \ominus$

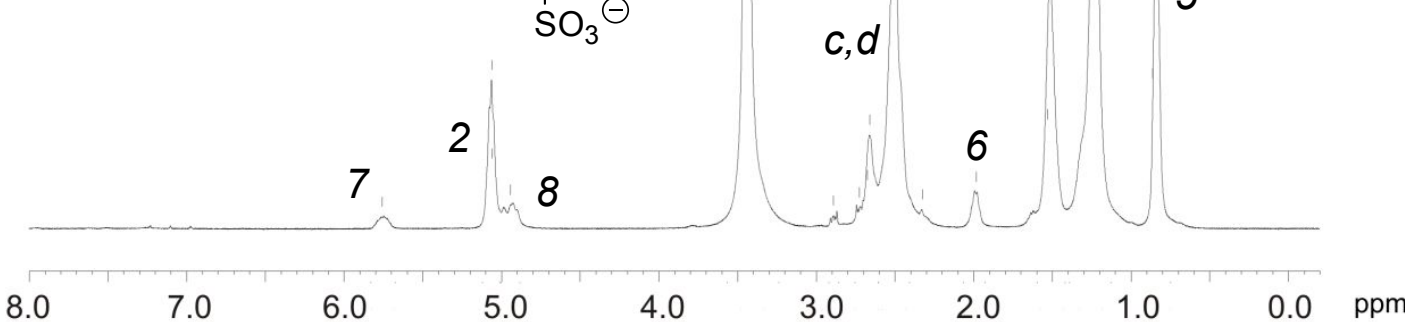

542 Figure 2. ${ }^{1} \mathrm{H}$ NMR spectra. (a) $\mathrm{PHO}_{(67)} \mathrm{U}_{(33)}$ in $\mathrm{CDCl}_{3}$ (b) $\mathrm{PHO}_{(67)} \mathrm{U}_{(13)} \mathrm{SO}_{3^{-}(20)}$ in DMSO-d6 
543

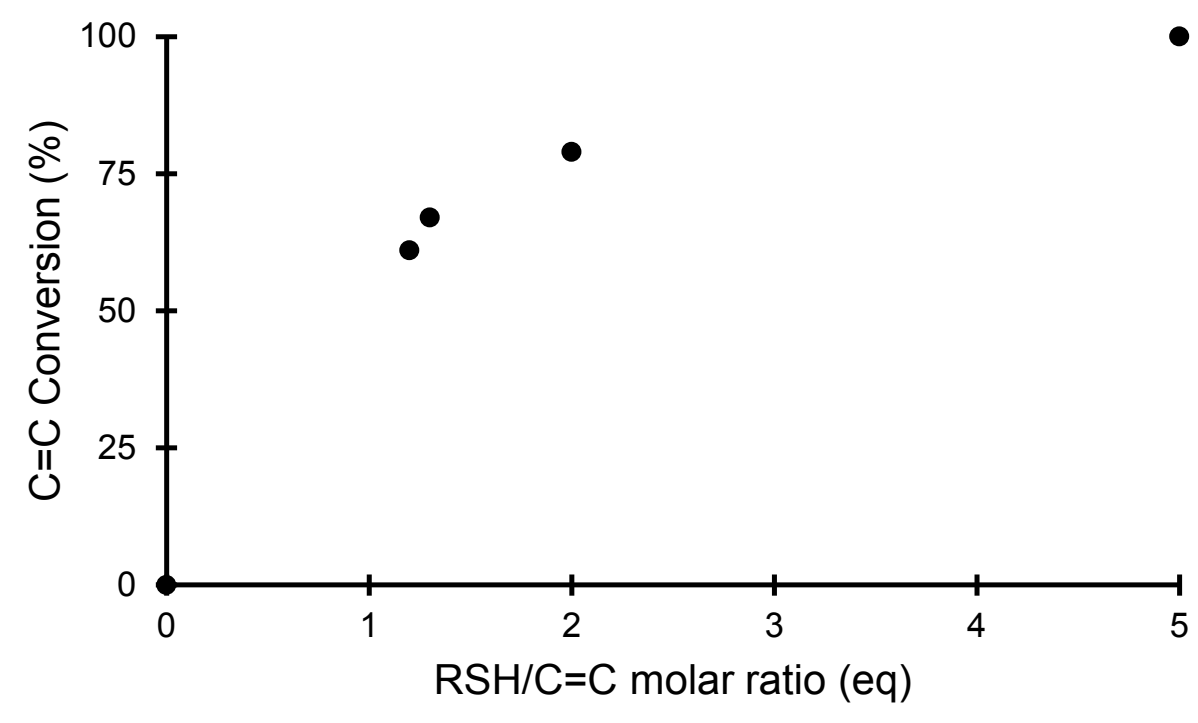

544

545 Figure 3. $\mathrm{C}=\mathrm{C}$ conversion of $\mathrm{PHO}_{(67)} \mathrm{U}_{(33)}$ determined by ${ }^{1} \mathrm{H}$ NMR 


\section{6}

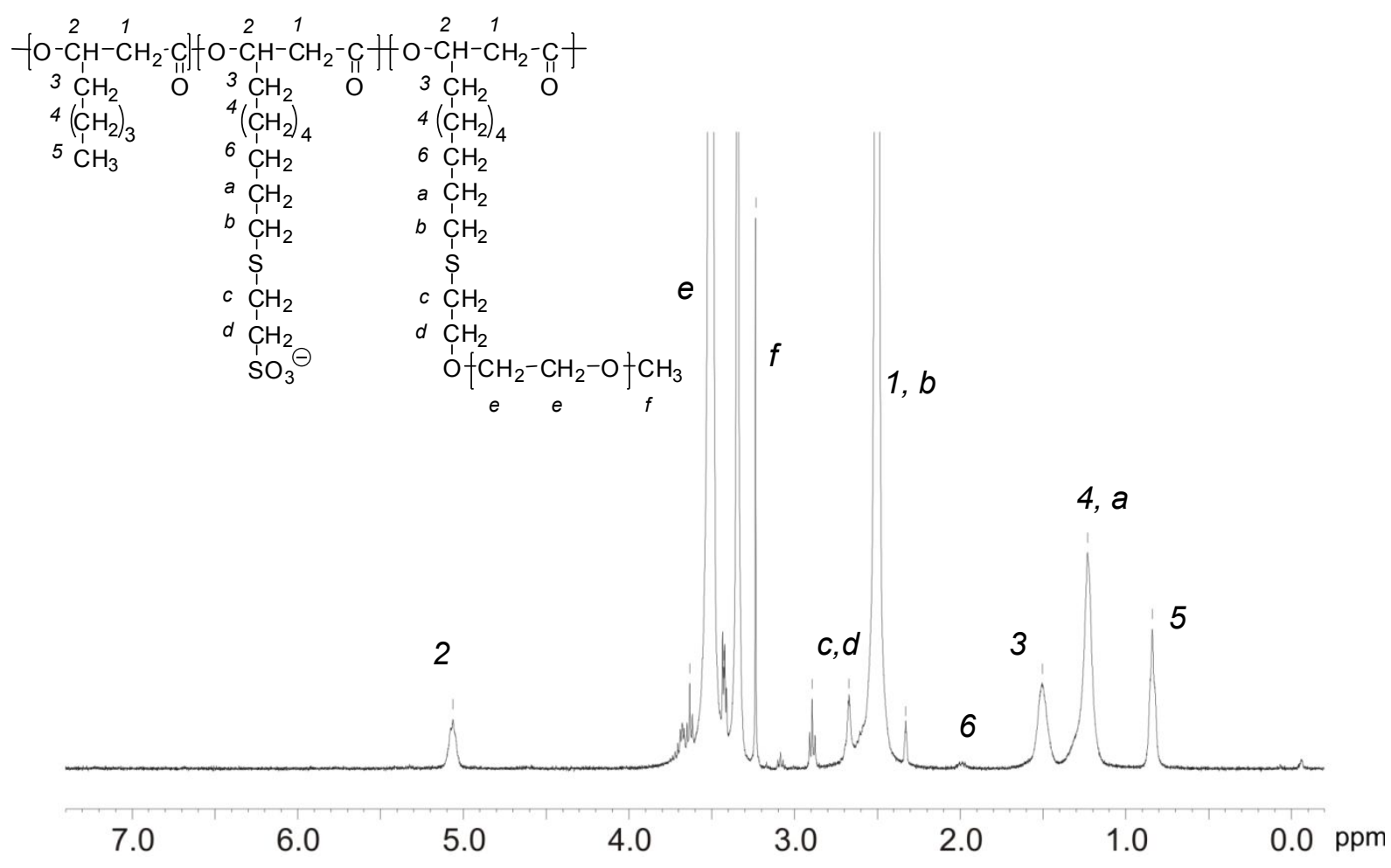

Figure 4. ${ }^{1} \mathrm{H}$ NMR spectrum of $\mathrm{PHO}_{(67)} \mathrm{SO}_{3^{-}(20)} \mathrm{PEG}_{(13)}$ in DMSO-d6.

549

550

551

552

553

554

555 

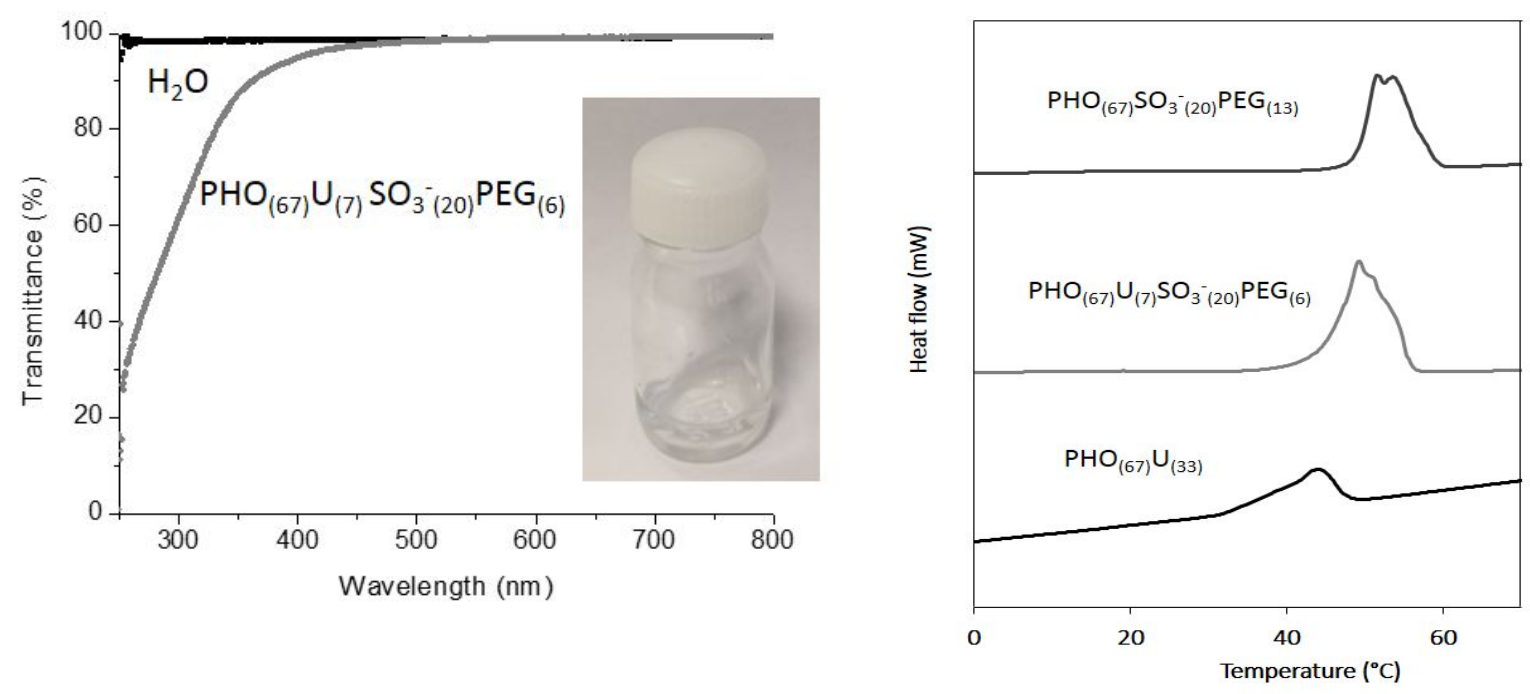

556

557

558

Figure 5. Transmittance measurements in ultrapure water and DSC curves. Only the first heating is reported.

559

560 


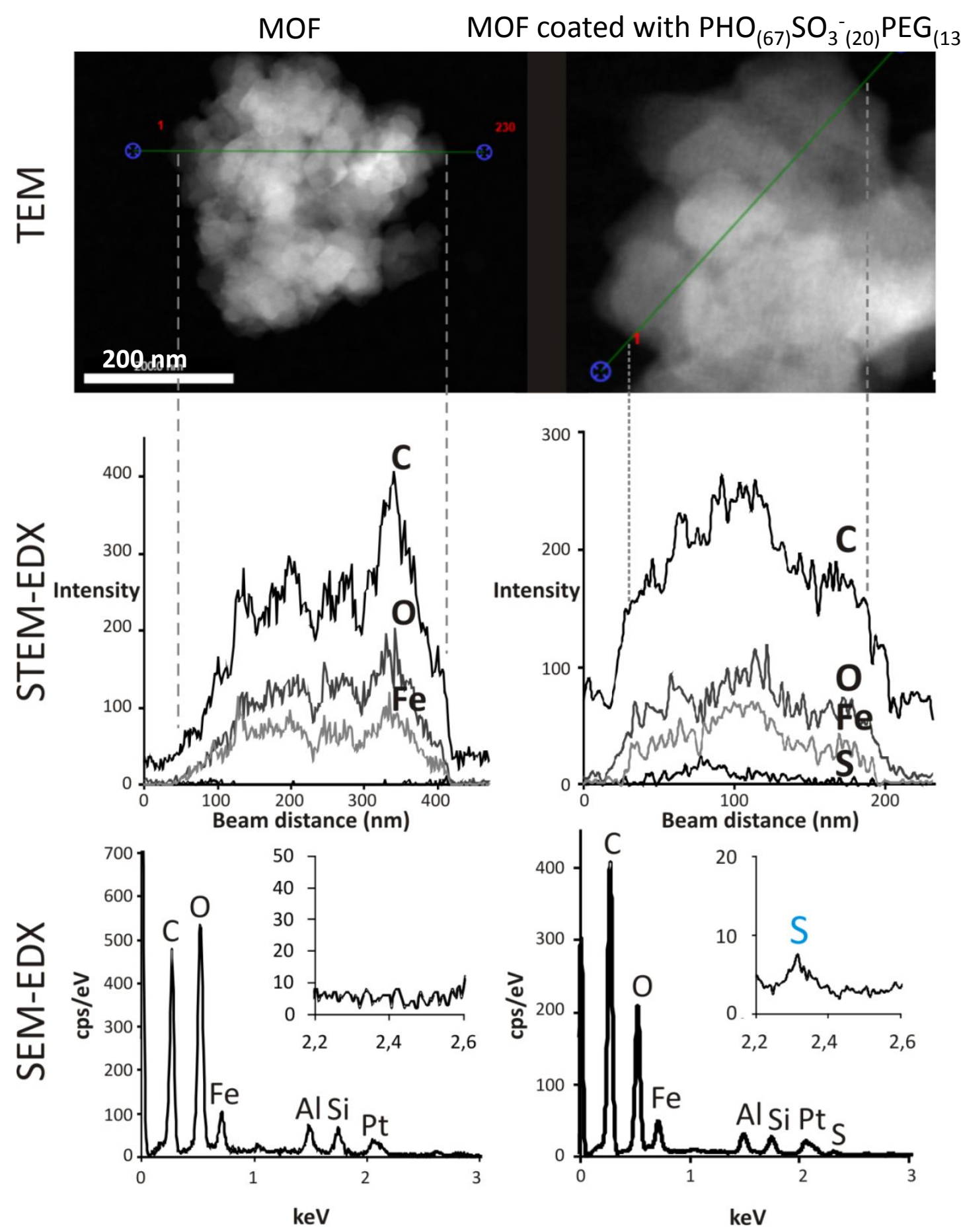

561

$\mathrm{keV}$

keV

562 Figure 6. TEM, STEM-EDX and SEM-EDX analysis of free MOF nanoparticles and coated

563 with $\mathrm{PHO}_{(67)} \mathrm{SO}_{3{ }^{-}(20)} \mathrm{PEG}_{(13)}$ 
564

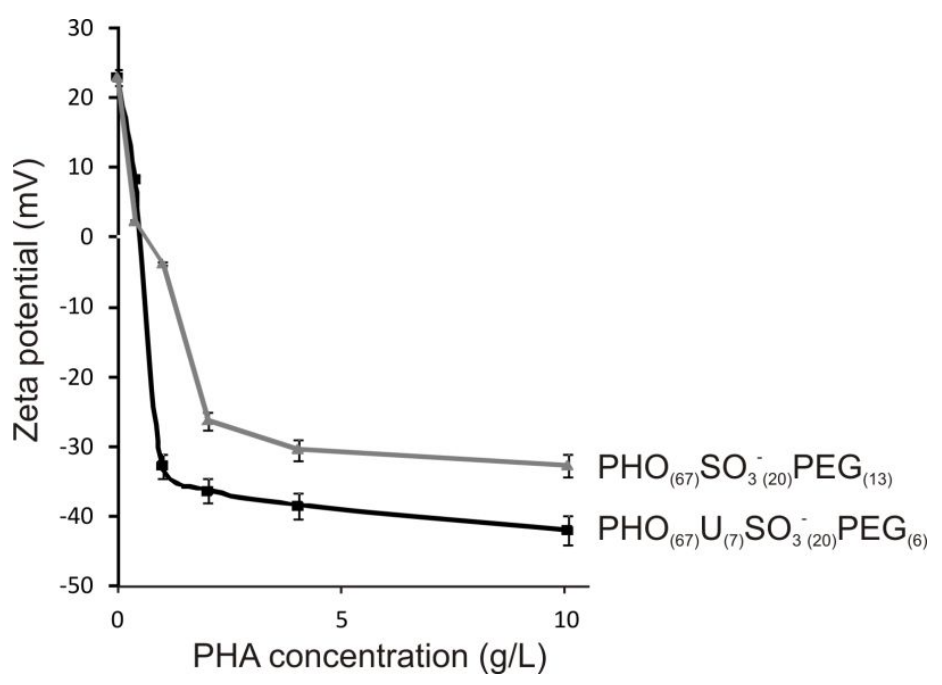

565

566 Figure 7. Zeta potential of MOF nanoparticles coated with $\mathrm{PHO}_{(67)} \mathrm{SO}_{3^{-}(20)} \mathrm{PEG}_{(13)}$ and $567 \quad \mathrm{PHO}_{(67)} \mathrm{U}_{(7)} \mathrm{SO}_{3^{-}(20)} \mathrm{PEG}_{(6)}$ 

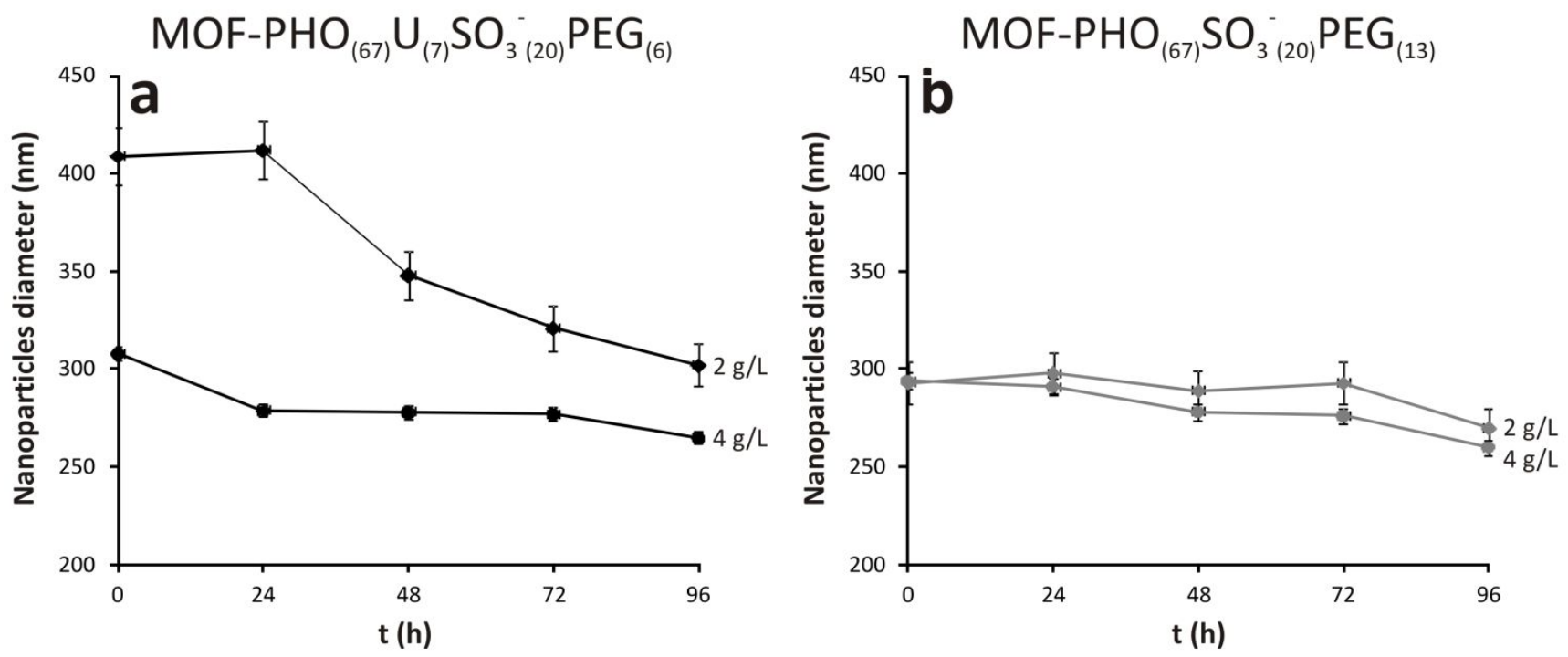

569 Figure 8. MOF-PHA hybrid nanoparticles diameters measured for $96 \mathrm{~h}$ in ultra pure water at 570 different copolymer concentrations. 

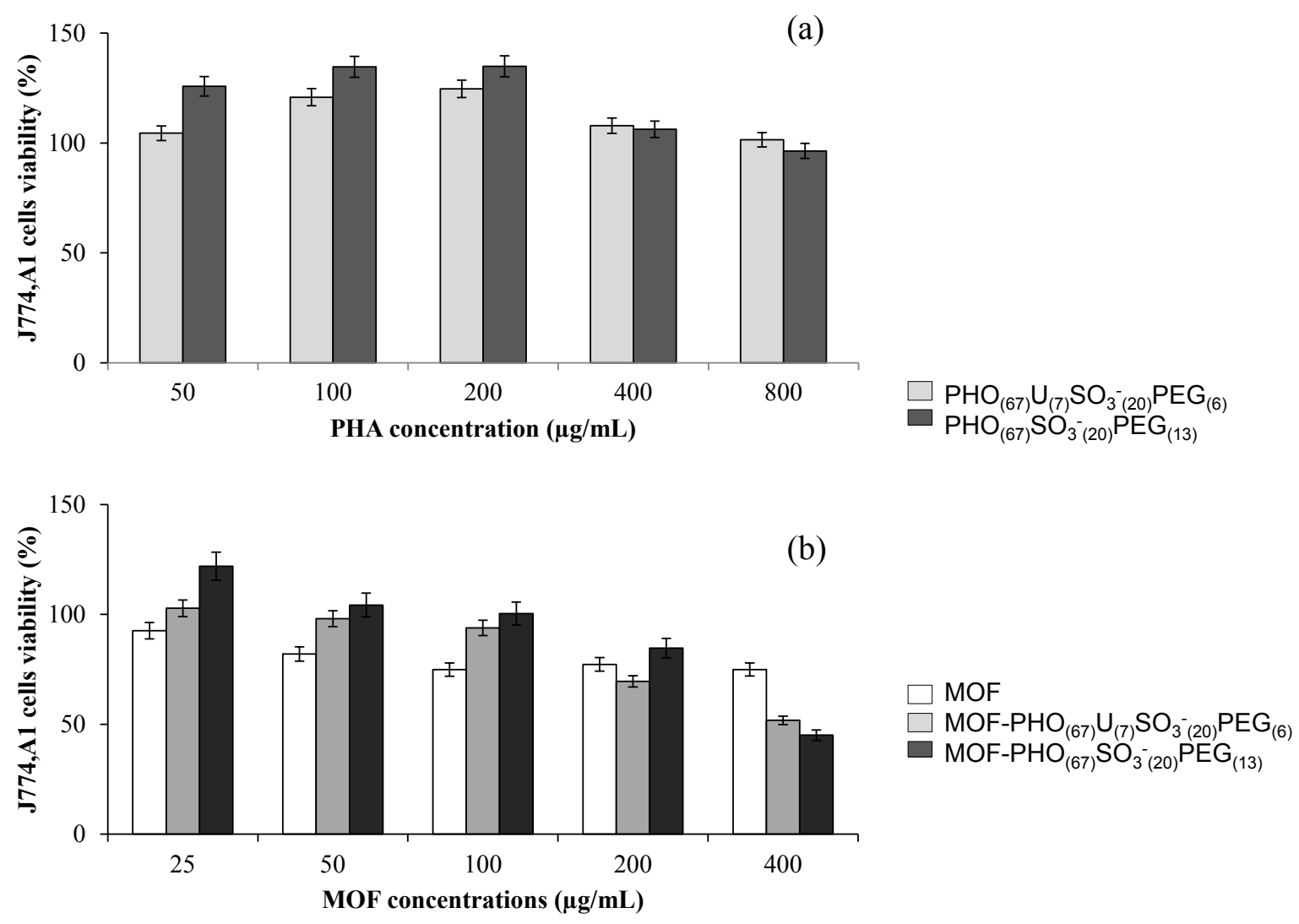

571

572 Figure 9. Viability of J774.A1 cells calculated using an LDH test, as a function of the 573 concentrations of copolymers (a) or nanoMOFs, native or coated with functionalized PHA (b), 574 after 24 hours of incubation. DMEM was used as control (100\%). Experiments were done in 575 triplicate. 

578 presence of MOF and coated MOF by $\mathrm{PHO}_{(67)} \mathrm{U}_{(7)} \mathrm{SO}_{3^{-}(20)} \mathrm{PEG}_{(6)}$ noted Cop1 or $\mathrm{PHO}_{(67)} \mathrm{SO}_{3^{-}}$ $579{ }_{(20)} \mathrm{PEG}_{(13)}$ noted Cop2

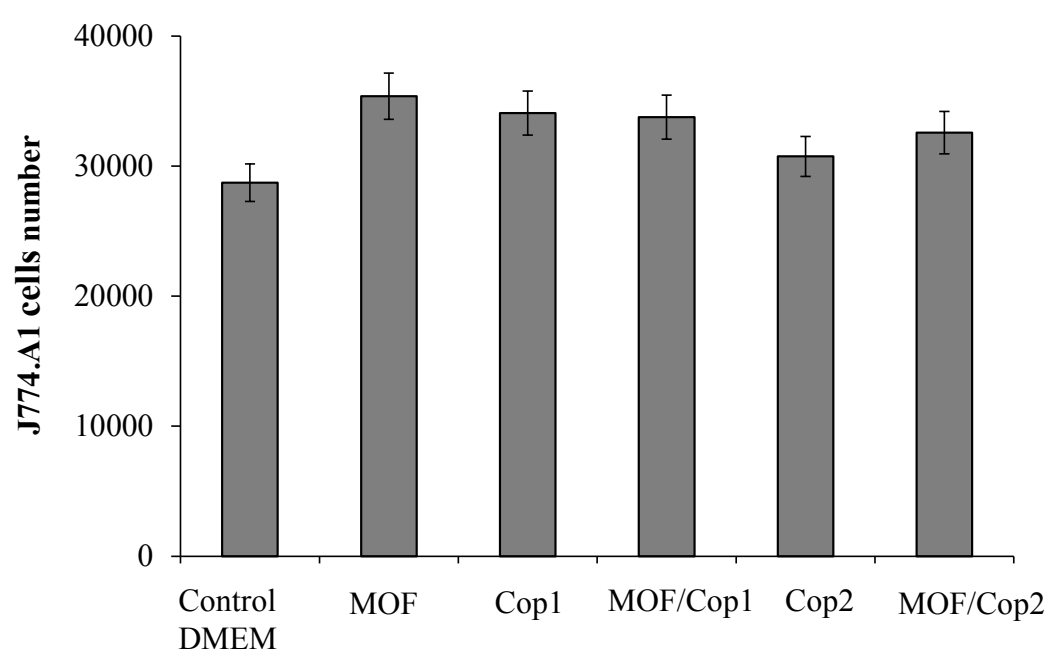

576

577 Figure 10. Number of viable J774.A1 cells determined by the RealTime Glo test for $42 \mathrm{~h}$ in 
581 Table 1. Characterization of PEG, $\mathrm{PHO}_{(67)} \mathrm{U}_{(33)}, \mathrm{PHO}_{(67)} \mathrm{U}_{(7)} \mathrm{SO}_{3^{-}(20)} \mathrm{PEG}_{(6)}$ and $\mathrm{PHO}_{(67)} \mathrm{SO}_{3^{-}}$ $582{ }_{(20)} \mathrm{PEG}_{(13)}$ polymers.

583

\begin{tabular}{|c|c|c|c|c|c|c|}
\hline \multirow[t]{3}{*}{ Samples } & \multicolumn{2}{|c|}{ Molar masses } & \multicolumn{4}{|c|}{ Thermal properties } \\
\hline & \multirow{2}{*}{$\operatorname{Mn}(\mathrm{g} / \mathrm{mol})$} & \multirow{2}{*}{ PDI } & \multirow{2}{*}{$\operatorname{Tg}^{\mathrm{c}}\left({ }^{\circ} \mathrm{C}\right)$} & \multirow{2}{*}{$\operatorname{Tm}^{\mathrm{d}}\left({ }^{\circ} \mathrm{C}\right)$} & \multicolumn{2}{|c|}{$\Delta \mathrm{Hm}^{\mathrm{d}}(\mathrm{J} / \mathrm{g})$} \\
\hline & & & & & PHA & PEG \\
\hline $\mathrm{PEG}_{2000}$ & $1,700^{\mathrm{b}}$ & $1.3^{\mathrm{b}}$ & - & 53 & - & 185 \\
\hline $\mathrm{PHO}_{(67)} \mathrm{U}_{(33)}$ & $40,000^{\mathrm{a}}$ & $1.7^{\mathrm{a}}$ & -40 & 44 & 14 & - \\
\hline $\mathrm{PHO}_{(67)} \mathrm{U}_{(7)} \mathrm{SO}_{3_{(20)}^{-}} \mathrm{PEG}_{(6)}$ & $24,000^{\mathrm{b}}$ & $1.1^{\mathrm{b}}$ & - & 49 & - & 82 \\
\hline $\mathrm{PHO}_{(67)} \mathrm{SO}_{3_{(20)}^{-}} \mathrm{PEG}_{(13)}$ & $29,500^{\mathrm{b}}$ & $1.1^{\mathrm{b}}$ & - & 52 & - & 132 \\
\hline
\end{tabular}

a Determined by $\mathrm{SEC}$ in $\mathrm{CHCl}_{3}$.

$585{ }^{b}$ Determined by $\mathrm{SEC}$ in $\mathrm{H}_{2} \mathrm{O} / \mathrm{LiNO}_{3}$

$586 \quad{ }^{c}$ Recorded from the second heating of DSC.

$587 \mathrm{~d}$ Recorded from the first heating of DSC, for copolymers $\Delta \mathrm{Hm}$ was calculated using the formula $\Delta H=\Delta H_{i} / W_{i}$, 588 where $\Delta H_{i}$ is the area of the DSC endothermic peak, and $W_{i}$ is the weight of PHA or PEG determined by ${ }^{1} \mathrm{H}$ RMN. 
591

592

593 594

595

\begin{tabular}{|c|c|c|c|c|c|c|c|}
\hline & Nanoparticles & $\begin{array}{c}C \\
(\%)\end{array}$ & $\begin{array}{c}O \\
(\%)\end{array}$ & $\begin{array}{c}\mathrm{Fe} \\
(\%)\end{array}$ & $\begin{array}{c}S \\
(\%)\end{array}$ & Ratio C/Fe & Ratio S/Fe \\
\hline \multirow{3}{*}{$\underset{\substack{n=1 \\
\infty}}{\stackrel{x}{1}}$} & MOF & 74.6 & 18.8 & 6.4 & 0.0 & 11.6 & 0.00 \\
\hline & MOF- $\mathrm{PHO}_{(67)} \mathrm{U}_{(7)} \mathrm{SO}_{3_{(20)}^{-}} \mathrm{PEG}_{(6)}$ & 76.7 & 16.6 & 5.9 & 0.8 & 12.9 & 0.13 \\
\hline & MOF- $\mathrm{PHO}_{(67)} \mathrm{SO}_{3^{-}(20)}^{-} \mathrm{PEG}_{(13)}$ & 77.7 & 16.4 & 5.2 & 0.8 & 15.1 & 0.16 \\
\hline \multirow{3}{*}{ 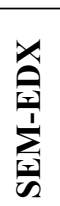 } & MOF & 55.2 & 38.3 & 6.5 & 0.0 & 8.5 & 0.00 \\
\hline & MOF- $\mathrm{PHO}_{(67)} \mathrm{U}_{(7)} \mathrm{SO}_{3_{(20)}^{-}} \mathrm{PEG}_{(6)}$ & 69.2 & 23.0 & 6.9 & 0.9 & 10.0 & 0.13 \\
\hline & MOF- $\mathrm{PHO}_{(67)} \mathrm{SO}_{3^{-}(20)}^{-} \mathrm{PEG}_{(13)}$ & 70.0 & 22.9 & 6.3 & 0.8 & 11.1 & 0.13 \\
\hline
\end{tabular}

Table 2. Average atomic composition of MOF nanoparticles determined by STEM or SEMEDX

596 
<smiles>CCC(C)CC(C)C(C)C(C)CC</smiles>

Unsaturated PHOU

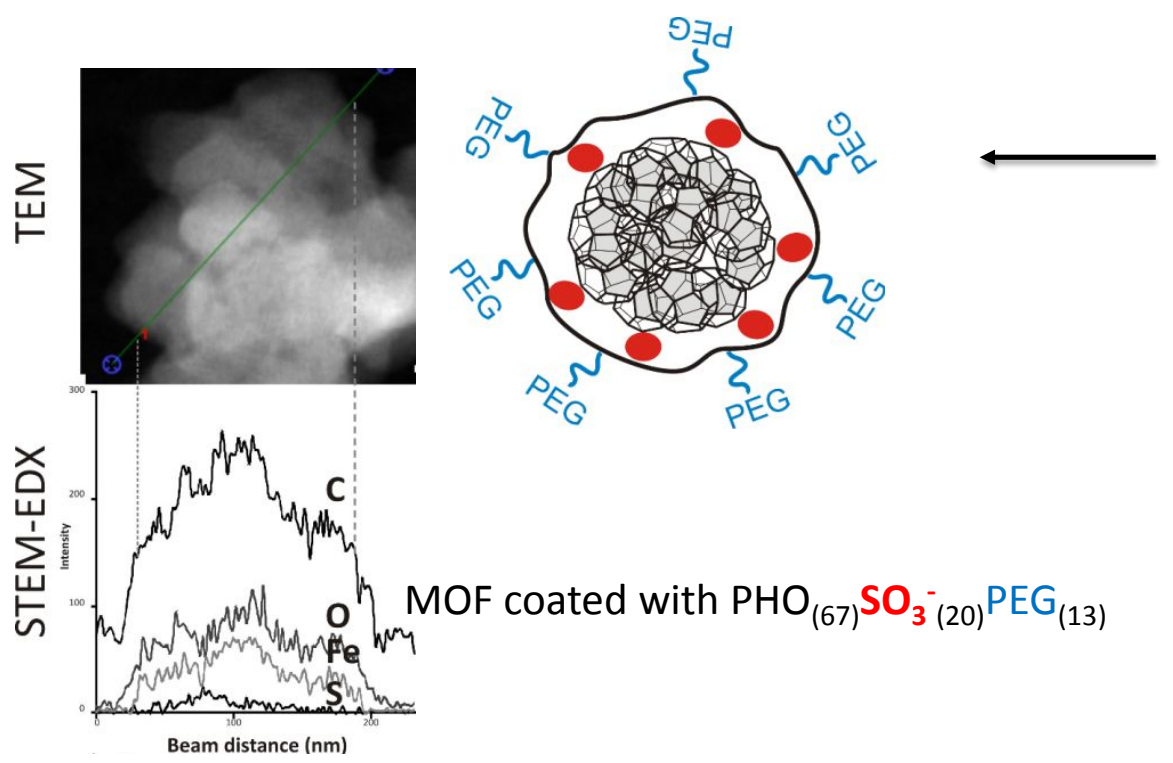

Two successive controlled photoactivated thiol-ene reactions

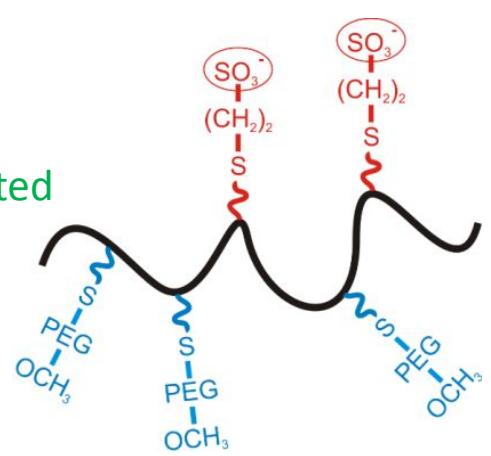

$\mathrm{PHO}_{(67)} \mathrm{SO}_{3}{ }^{-}(20) \mathrm{PEG}_{(13)}$

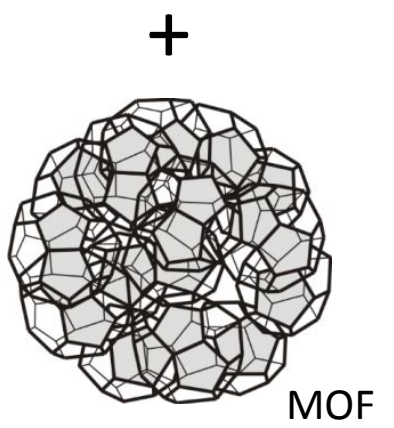
603 